\title{
The Benefits of Telephone Services in the Villages and as Media Technology
}

\author{
Tomi Oktavianor ${ }^{1}$, Roy Valiant Salomo ${ }^{2}$, and Lina Miftahul Jannah ${ }^{3}$ \\ \{tomi.oktavianor@ulm.ac.id ${ }^{1}$, roysalomo2357@gmail.com², miftahul@ui.ac.id ${ }^{3}$ \} \\ Faculty of Social dan Political Science, University of Lambung Mangkurat, \\ Banjarmasin, Indonesia ${ }^{1}$, Faculty of Administrative Science, University of Indonesia, Depok, \\ Indonesia ${ }^{2,3}$
}

\begin{abstract}
This paper describes the benefits of telephone services in the village. The method of data collection was the interview. It was conducted with five users and five operators as key informants. The collected data was analyzed using Actor-Network Theory-graph syntax. It was found that the benefit of telephone services in the villages was limited to social needs, but there were no economic benefits. Therefore, this paper proposes the need to enroll non-human actors, such as media technology, to meet between sellers and buyers. In the future, other research needs to continue how appropriate a media technology could promote superior products in the village.
\end{abstract}

Keywords: Actor-Network Theory, Media Technology, Telephone Service.

\section{Introduction}

Telephone in the village has succeeded in providing telecommunications access, but how the telephone provides economic benefits to the village community still needs to be investigated. The presence of telecommunications technology in the village has two possibilities. The appearance of technology and ease of access in the village according to Galloway does not necessarily change the state of the rural economy [1]. Another possibility is that telecommunications technology can play a role in economic activities leading to economic prosperity and/or reducing poverty [2]; [3]; [4]; [5].

According to Bedia \& Rajesh, so far the potential village market has not been utilized [6]. The presence of telecommunications technology can take advantage of this village market opportunity [6]; [7]. Based on Verma, there will be a growth opportunity in the village market if the presence of telecommunications technology may provide a connection with urban areas [7]. The problem so far according to Richmond, Rader \& Lanier is that, telecommunication services are underutilized [8]. With this, the research question is how can telephone presence in the village benefit, especially economic benefits and how do barriers open up village market opportunities?

Madden asserts that telecommunications services contain network effects, which leads to economic prosperity [5]. If telephone users in the village as sellers of village products, the village market opportunities will be open if there is intensive interaction with buyers [7]. The network of opening up wide-ranging village market opportunities requires a buyer presence. Referring to the Actor-Network Theory [9], the market is viewed a network consisting of human (such as sellers, buyers) and non-human actors (such as telephone). The market is the 
relationship between sellers and buyers, but the village market conditions that are still isolated from the presence of buyers require media technology, which is not only telephone technology [3]; [8]; [10]. With this, research aims to determine media technology that can overcome obstacles to take advantage of village market opportunities.

\section{Method}

This research was conducted in the Lebak Regency. This district is categorized as an underdeveloped region and has a total of 345 villages [11], 199 of which receive universal telephone services and other villages receive direct telephone services from various private providers. The key informants were selected with the criteria of having firsthand knowledge of the village telephones usage. There were five non-Universal Service Obligation telephone users and five former Universal Service Obligation operators. Data collected was analyzed with Actor-Network Theory-graph syntax, starting with identifying actors involved in the telephones usage. The Actor-Network Theory-graph syntax determines a technology tool that may overcome the barriers of seller and buyer relations.

\section{Result}

The Lebak region is one of the most remote areas in Java and is still categorized as an underdeveloped region, "closed" from the outside world due to the relatively difficult access to this place. Lebak has a very wide area with 28 sub-districts, and sparse residents with a density of 417 people per $\mathrm{km}^{2}$ [11]. For remote areas, the presence of telephone services is welcomed by the village community. The difficulty of communication between residents including the "outside world" has been overcome by the presence of telephones. The benefits of telephone service for villagers are the ease of delivering and receiving messages/information.

Villagers use telephones for various needs. The use of telephones by the villagers is divided into three matters: firstly social affairs, secondly work affairs, and thirdly buying and selling business. The first and second affairs are the process of translation (T1) of affairs in social relations, communication with family, friends, and colleagues (see figure 1). Social affairs, a telephone is used as a means of communication in family relationships and friendships. The telephone is used to determine the condition of the family's health, inform the disaster and accidents, and other needs.

As for the government apparatus, the telephone is used by the village officials, district and sub-district officials in coordinating their daily work affairs such as meeting preparation and others. Work affairs for the village community, a telephone is used as a communication tool in finding job and employment affairs. For family members who work in big cities such as in Jakarta, or abroad such as in Saudi Arabia, Malaysia, Hong Kong, they can deliver messages and receive messages from their employers when they are home. 


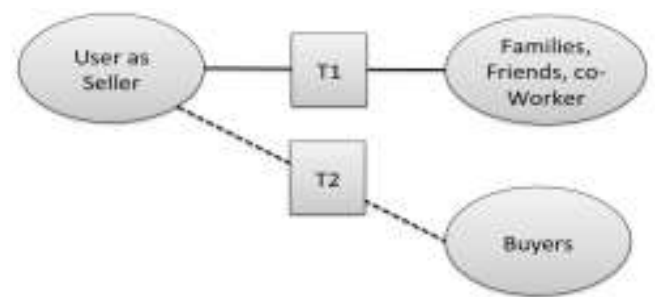

Fig. 1. Model Analysis of the Benefits of Phones with ANT-gs

Remarks. The connecting line (T1) indicates a relation occurs, and the dashed line (T2) indicates that there is no relation.

The trade business (T2), the telephone has been used to find buyers and/or sell land, agricultural and plantation products, and to sell superior products. This benefit is not optimal because the prospective buyers contacted are limited to those who are known. The market for superior products is "closed" or not yet known by the wider community, such as superior products in the form of handicrafts from the Baduy tribe. For residents who have received chat services such as WhatsApp application, it is also limited to people they know or to those who have visited Kanekes Village as a place of residence for the Baduy Tribe. User and telephone relations cannot invite buyers from outside the Lebak area. The availability of telephones is limited to relations with those who are known only, so it is impossible to inform various superior products of the village market. Constraints occur in promoting superior products, so they cannot attract buyers who are in urban areas or outside the Lebak area.

\section{Discussion}

The availability of access to telephone services in the village has benefited the population, but more to social benefits. Transportation facilities that are very minimal make the presence of telephones a communication solution for the village community. Benefits of the availability and access to telephones in rural areas are providing easy communication for residents in the case of social affairs and work matters. The village community as a telephone user has no obstacles in using it for matters of social relations and employment relations. The availability of telephones provides convenience, fast, efficiency, and without limits of distance in delivering messages/information.

The presence of telephone in the village has not been maximized as a media that connects village sellers and buyers outside the Lebak area. This is in line with the opinion of Galloway that the presence of telephones in the Lebak region has not provided maximum economic benefits [1]. Small businesses in rural areas cannot reach modern customers effectively [8]. This obstacle occurs because of the limitations of telephone technology in opening up village market opportunities and/or limitations of telephone technology to bring buyers outside the Lebak area. Phone technology is only limited as a medium of communication between sellers in the village and known buyers. The extensive relationship between sellers and buyers does not occur only with the presence of telephones, because of the limitations of telephone performance as a communication tool that only connects to known people. In other words, the presence of a telephone cannot expand the village market network.

Extending the village market network or overcoming barriers to the relations of sellers and buyers outside the Lebak area needs to enroll non-human actors [12] or in other words 
need to adopt other media technology [3]. Overcoming these obstacles requires the presence of media technology, some of which are web-based applications and Short Message Service gateways [8]; [10]. The presence of this media technology can bring together sellers and buyers (see figure 2).

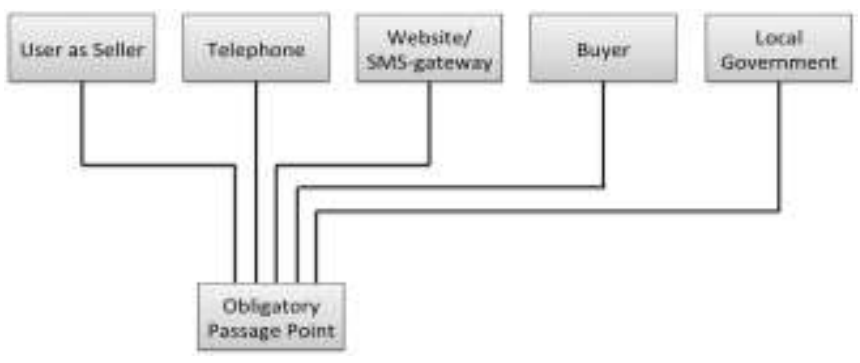

Fig. 2. Actors in Rural Market Network

A website is needed because it is the entrance for potential buyers to know the products in the village market. About $81 \%$ of buyers use search engines such as Google, Bing, and others, looking for information before making a decision to buy something [13]. Therefore, if the village market does not have a website, then there is no opportunity to "persuade" potential buyers [8].

The majority of the population with a telephone with an Short Message Service facility can use a telephone to promote their products through an Short Message Service gateway. Short Message Service gateway is a way of delivering information from the owner of the telephone with Short Message Service and information can be returned by the administrator to telephone users [10]. Databases sent by sellers can be displayed by web-based applications to be known by all prospective buyers. Thus, the presence of media technology such as webbased applications and Short Message Service gateways may open opportunities for buyers and sellers to meet [8].

Wherever and whatever the business, there is a problem in adopting media technology [8]; [10], so that the district government initiatives are needed to provide it. The district government is also the administrator of the management of web-based applications and Short Message Service gateways because broadband district access is available in the district capital. Thus, the obligatory passage point (see figure 2) is the first step in overcoming barriers between seller and buyer relations. Presenting web-based applications and Short Message Service gateways complement the limitations of telephone performance, as well as the actions of the district government as web-based application and Short Message Service gateways providers and administrators.

In the future, research needs to be sought to match media technology that not only promotes superior products in the village market but also other needs. Web-based applications may provide a variety of information as needed, a window of information on resources, culture, and other important issues [3]; [10] such as promoting tourism, security needs, and others. 


\section{Conclusion}

The presence of telephone in the village will not provide economic benefits, but it is need the government's initiative. The media technology such as Short Message Service gateway and Web-based application add value to the presence of telephone. Then, this media does not only have an impact on economic benefits, but also it creates an atmosphere of governance. This will facilitate easy interaction between local government and the villagers, such as to inform a government program, to secure a village territory, and to know the aspirations of the villagers.

Acknowledgements. This research was supported by Program of International Publication in the Faculty of Administrative Sciences, with funding from Universitas Indonesia (UI). The authors would like to thank the reviewers, especially to Universitas Muhammadiyah Sidoarjo (UMSIDA) that hold the International Conference on Emerging Media, and Social Science December 7-8, 2018 Banyuwangi, Indonesia.

\section{References}

[1] L. Galloway, "Can broadband access rescue the rural economy?," J. Small Bus. Enterp. Dev., vol. 14, no. 4, pp. 641-653, 2007.

[2] C. Casanueva-Reguart, “The Regulatory Environment,” J. Inf. Policy, vol. 3, no. July, pp. 267303, 2013.

[3] H. E. Hudson, "Digital Diversity: Broadband and Indigenous Populations in Alaska," J. Inf. Policy, vol. 1, pp. 378-393, 2011.

[4] S. C. Huang and J. L. Cox, "Establishing a social entrepreneurial system to bridge the digital divide for the poor: a case study for Taiwan," Univers. Access Inf. Soc., vol. 15, no. 2, pp. 219 236, 2016.

[5] G. Madden, "Economic welfare and universal service," Telecomm. Policy, vol. 34, no. 1-2, pp. 110-116, 2010.

[6] D. D. Bedia and R. Gupta, "A study on opportunities and problems in rural market," Int. J. Manag. Prudence, vol. 5, no. 2, pp. 63-70, 2013.

[7] S. K. Verma, "Rural Marketing in India - Challenges and Opportunities," Anusandhanika, vol. 5, no. 1/2, pp. 16-22, 2013.

[8] W. Richmond, S. Rader, and C. Lanier, "The 'digital divide' for rural small businesses," J. Res. Mark. Entrep., vol. 19, no. 2, pp. 94-104, 2017.

[9] V. B. Latour, "On actor-network theory: A few clarifications," Soz. Welt, vol. 47, pp. 369-381, 1996.

[10] A. Salim, "Management Information in Rural Area: A Case Study of Rancasalak Village in Garut, Indonesia," Procedia Technol., vol. 11, pp. 243-249, 2013.

[11] BPS Lebak, Lebak Dalam Angka. 2016.

[12] M. Callon, "Some Elements in a Scoicology of Translation: Domestication of the scallops and fishermen of St. Brieue Bay," in Power, Action, Belief: A new sociology of knowledge, L. John, Ed. London: Routledge and Kegan Paul, 1986, pp. 196-233.

[13] S. Morrison, "81\% of shoppers conduct online research before buying," 2015. [Online]. Available: www.adweek.com/socialtimes/81-shoppers-conduct-online-research-making-purchaseinfographic/208527. [Accessed: 02-Aug-2018]. 